EL RELATO CORTO EN

EL CINE. LITERATURA

EN 3-D: 'MEMENTO' DE

CHRISTOPHER NOLAN

$(2000)$

\section{Las adaptaciones}

\section{literarias en la gran}

\section{pantalla: una cuestión}

\section{de lenguajes}

\section{David Caldevilla Domínguez}

\author{
Profesor Relaciones Públicas y Gabinete \\ de Comunicaciones \\ Facultad Ciencias de la Información. Universidad Complutense \\ de Madrid. Avenida Complutense s/n. 28040, Madrid (España) - \\ Tlfn: 913942167 - Email: davidcaldevilladimagometrica.com
}

\section{Resumen}

La narrativa literaria y la cinematográfica se erigen como dos lenguajes separados por la sustancia expresiva en la que se basan. En el caso de las adaptaciones literarias, estas diferencias se manifiestan otorgando una especial ventaja al cine ya
Palabras clave

Memento, adaptaciones

literarias, narrativa

cinematográfica, cine negro

Key Words

Memento, literary adaptations, film narrative, film noir

\section{Abstract}

Literary and cinematic narrative stand as two languages separated by the expressive substance on which they are based. In the case of literary adaptations, these differences give cinema a special advantage, as there are expressive licenses which are impossible to find in a written text. The present article analyses one of the most surprising, innovative and rupturing adaptations in film history, Memento, which exploits, like no other film before it, the possibility of breaking the so-called conventional or lineal narrative thread, in order to generate a plot in which the viewer becomes a reader-author. This cinematic trope reaches its best expressive capabilities in two genres (understanding genre not only as form, but also as theme) as old as cinema itself: science-fiction and film noir. 'Memento' is to be included within the latter, and has been chosen to better demonstrate those possibilities that cinema gives to literature by means of 
que existen licencias expresivas imposibles para el texto. En el presente artículo se analiza una de las adaptaciones más sorprendentes, innovadoras y rupturistas de la historia del cine, 'Memento', que explota, como ninguna otra antes, la posibilidad de romper el hilo narrativo llamado convencional o lineal, para pasar a generar una trama en la que el espectador se erige en lecto-autor. Este tropo cinematográfico halla sus mejores capacidades de expresión en dos géneros (entendiendo género no sólo en su aspecto formal, sino en el temático) tan antiguos como el cine mismo: el de ciencia-ficción y el negro, género este último al que pertenece la película analizada, elegida para mejor demostrar esas posibilidades que el cine ofrece a la literatura a través de las adaptaciones. El hecho de que 'Memento' esté basada en un relato corto permite que, además, se consideren las ventajas que este tipo de relatos ofrece a los adaptadores-guionistas frente a los relatos largos como las novelas o las obras teatrales.

\section{Introducción}

Nuestro objeto de estudio se centra en analizar el concepto de adaptación en dos vertientes: en el plano formal, en cuanto que el relato corto, ésta es nuestra hipótesis, se adapta mejor al cine; y en el plano de contenidos, en cuanto que el cine negro y el de cienciaficción, en tanto géneros temáticos, se muestran como los mejores para poder dar el salto del papel a la gran pantalla. Para delimitar nuestro objeto, emplearemos como base de nuestro análisis un texto corto anterior a la película, pero publicado tras ésta, en 2001, en la revista 'Esquire' de los EE.UU.: Memento mori (Recuerda que morirás, frase que se empleaba en la Roma clásica, dicha por un esclavo ubicado adaptations. Furthermore the fact that this film is based on a short story allows us to consider the advantages that this kind of story gives to screen writers/adapters in contrast with long stories such as novels or theatre plays. tras el general triunfante que desfilaba en carro por las calles imperiales para conmemorar una reciente victoria en loor de multitudes) y su plasmación cinematográfica en el año 2000: ' $M e$ mento'. Su elección viene justificada por la alambicada adaptación guionística del relato, pasando la narración literaria de la historia desde una naturaleza temporal lineal o clásica, a una cinematográfica "a saltos" temporales ya prolépticos ya analépticos. En ambos casos el autor-escritor literario coincide (del relato corto y del guion), Jonathan Nolan, siendo autor de la parte audiovisual su hermano, Christopher Nolan, quien también es coguionista. 


\section{Objetivos}

Los objetivos derivan de la propuesta inicial de análisis textual literario y audiovisual cinematográfico, en tanto en cuanto concomitantes, a partir de las adaptaciones que algunos textos han tenido en la gran pantalla. Finalmente se considerará si la cinematografía, a partir de sus propios elementos narrativos, no contemplados en la literatura, supone una mejora o empeoramiento del original. Es decir, la finalidad de nuestro análisis es confirmar si se producen en las adaptaciones cinematográficas mejoras gracias a las peculiaridades de su narrativa a través de la aplicación de sus propias herramientas de análisis estructural y de contenidos vehiculados. No se ha entrado en otras consideraciones como las adaptaciones de novelas u obras de teatro ya que nuestro objetivo es analizar qué aporta el cine a las posibilidades narrativas de historias cortas que no encorsetan la línea narrativa debido a su pequeña extensión habitual frente a esos otros grandes relatos, difícilmente moldeables por la cantidad de información contenida y que sólo permitiría, a nuestro juicio, o una plasmación formal más o menos brillante pero mucho menos creativa desde el punto de vista de las posibilidades del lenguaje cinematográfico o una drástica diferenciación con la fuente.

\section{Metodología}

Los métodos de investigación empleados, a partir de una fuerte componente de analítica textual, son el analíticosintético y el comparativo. Inicialmente se analiza la aplicación de esquemas narratológicos propios de la narrativa cinematográfica en comparación con la literaria ya que tratamos el tema de las adaptaciones de relatos cortos. Para ello hemos considerado que el estudio de caso sería el punto final de la metodología al aplicar la base teórica a la película 'Memento', adaptación de un relato corto, por ser arquetípica del género negro y del tipo de adaptaciones que interesan para desarrollar el objeto del presente estudio. 


\section{Las adaptaciones cinematográficas $y$ 'Memento'}

Uno de los hitos cimeros de la ciencia ficción de todos los tiempos fue, sin duda, '2001, una odisea del espacio' de Stanley Kubrick (1968). Lo que se muestra más oculto al gran público es que esta cinta se basa en un relato corto, de unas 8 páginas, de Arthur Charles Clarke titulado El Centinela: De ahí que el propio autor contribuyera a redactar el guion y, por este motivo, surgieran amplias discrepancias con el director inglés, ya que éste, Kubrick, pretendía mantener oscura la historia contada al gran público, sin concesiones ni pistas explicativas, y el escritor, Clarke, postulaba que, sin ellas, el espectador perdería el sentido mismo de la historia. Como quiera que el maniático Kubrick no diese su brazo a torcer, el propio Clarke tuvo que novelizar el guion para que pudiéramos, los espectadores, entender que la nave simboliza un espermatozoide que va a inseminar las estrellas y que "en un lapso de tiempo demasiado breve para poder ser medido, el espacio giró y se torció sobre sí mismo", lo que llevó al protagonista (Dave Bowman) a emprender un viaje, casi psicodélico, fuera de la mortecina nave espacial hasta llegar a un "espacio sin tiempo".
Este ejemplo nos sirve para ubicar el aspecto dual del presente artículo: ¿Supone el lenguaje cinematográfico una Tercera Dimensión sobre el texto escrito, radicalmente nuevo que lo completa y enriquece o supone una simple transcripción? Y en el caso concreto de los relatos cortos -el epicentro de nuestro estudio-, planteamos una nueva incógnita: ¿Es el mejor género, en lo formal, para ser adaptado por no tener que recurrir el guionista cinematográfico a la esclavitud que supone un relato largo, por ejemplo una novela (ya que el teatro posee otras aportaciones distintas y más directas al cine), dada su extensión, la cual obligaría a los adaptadoresguionistas a abocar en un exceso de literalidad y mimetismo al texto? Obviamente el género, en tanto en cuanto temática, ha de ser tratado, pero esta nueva vía, por prolija, no puede ser abordada plenamente sin sobrepasar los límites de un artículo enfocado $a b$ origine en estructuras formales. Es cierto que, ineluctablemente, partimos de la base de que mayoritariamente el género de la ciencia-ficción y el negro se han mostrado como muy proclives a esta transustanciación de formas narrativas. 
Como bien indica José Luis SánchezNoriega (2000, pp. 65 y 66):

Entendemos por literatura básicamente la novela y el teatro; y dejamos de lado otras formas escritas (poesía, reportajes periodístico, ensayo, etc...) que puedan inspirar argumentos cinematográficos. Del mismo modo, nos referimos al mayoritario cine narrativo y prescindimos del documental y del cine experimental.

No coincidimos con algunos autores clásicos, como Pere Gimferrer (1994) en afirmar que existe una base que radicaliza las diferencias ya que la sustancia narrativa del cine son las imágenes (soslayando así este autor catalán el sonido) y en el caso de la literatura son las palabras. Por ello es más correcto aludir a situaciones comunicativas distintas formalmente pero que pueden coincidir en amplios elementos de contenido (Caldevilla, 2005).

También es cierto que en nuestro mundo económicamente centrípeto, algunas películas han simplificado el valor estético de sus textos de referencia en dos vertientes a cual más empobrecedora: en primer lugar la de adaptaciones a presupuestos sobre necesidades de la historia (grandes decorados, movimientos de masas, ambientación, aggiornamentos de tramas, recurso a elipsis o metonimias simplifi- cadoras...); y en segundo, la de la reducción de situaciones, tramas, diálogos en pos de sincronizar con los gustos del gran público, claudicando a modas comercialmente rentables en taquilla (es inevitable hablar aquí de 'Troya' de Wolfgang Petersen, 2004).

No trataremos en estas páginas de ahondar más en esta disputa casi secular, pues desde los mismos orígenes de la séptima arte los escritores se han manifestado sobre las adaptaciones de sus obras y de las ajenas, incluso aunque varios de ellos cruzaran el Rubicón que los convirtió en guionistas o vendedores de los derechos para la pantalla de sus obras más reputadas (como ejemplo de lo anterior citaremos que el autor español más "adaptado" por el balbuciente Hollywood fue Vicente Blasco Ibáñez, plusmarca que aún perdura). Baste decir que pocos han sido, y siguen siendo, los escritores que se han sentido satisfechos con las traslaciones de sus páginas a la sala.

Autores hay, como Villanueva (1999) o Fernández (2000) quienes consideran que la palabra o concepto "adaptación" ha simplificado una realidad que para ellos es más adecuadamente señalada como "recreación", "variación" o más directamente "transposición". En esta línea hallamos el artículo cimero de Thomas Leitch (2008) titulado "Adaptation studies at a crossroads" en el 
que enumera todas las corrientes actuales de pensamiento sobre el tema, tomando como puntos cardinales cuatro tipos de estudios al respecto según su importancia y formato. Así los divide en: colecciones de ensayos nuevos, libros de texto, monografías centradas en la relación entre la adaptación y la apropiación y otras monografías ya generales sobre la adaptación. Este trabajo señero en el campo de las adaptaciones, demuestra como la mayoría de los autores aún se mantiene anclada en la relación de identidad entre lo que él llama "texto fuente" y la versión en celuloide.

En sus páginas se llega a afirmar que: "A falta de la bala de plata que libere los estudios de adaptación de la mano muerta de la literatura, la taxonomía y la evaluación, la tentación de sucumbir a estas ortodoxias es más grande en los ensayos" "ii.

Quizá sea un aserto excesivo pero define la voluntad de crear una nueva realidad taxonómica exclusiva para las adaptaciones, o, si no exclusiva, sí menos dependiente de su matriz impresa.

Pese a que la intención de este profesor de la Universidad de Delaware (EE.UU.) no sea aportar un trabajo concreto de aproximación personal al fenómeno adaptacional (sit venia verbis) sino enumerar las corrientes existentes, destaca, en su análisis de estos trabajos ajenos, la enumeración reagrupadora que de las diversas ideas de los variados autores (y en ello reside la importancia de su artículo) e investigadores de lo que significa "adaptación" hace. Así, se cuestiona como herramienta koiné los siguientes puntos para entender ante qué grado de (buena o mala) adaptación nos hallamos (y respondemos sobre el caso de 'Memento':

1. ¿La película en cuestión traiciona su fuente literaria?. 'Memento' es fiel al espíritu del relato corto.

2. ¿La adaptación trata de establecerse como una transcripción o una interpretación de su fuente? Sí, ya que la fuente es escasa en cuanto a anécdota para un largometraje.

3. ¿La película se adapta a su fuente literaria, según los nuevos contextos culturales o históricos a los que se dirige? Sin duda, sí.

4. Si la película más allá de su fuente literaria original, hace que la fuente quede bastante eclipsada por la película, ¿merece una mayor consideración en cuanto a interés por derecho propio? Sí, es una historia más completa y compleja.

5. ¿Es posible que una película para recrear lo que podría tildarse como más propio de los aspectos literarios de su fuente, desafiando los modelos específicos de adaptación 
mediante la implantación de los recursos inesperados del cine, llevaría a plantear cuestiones que antes se tomaban como patrimonio exclusivo de la literatura (casi siempre, en este caso, la novela)? No, pues posee su propio código visual.

6. ¿Se halla la película, así como su texto fuente, dentro de su contextualización histórica y cultural propia? Sí, ya que es una historia no ligada a una época concreta pero sí a un estilo de vida.

7. ¿Qué cuestiones aportan los productos literarios tipologizados sobre los diferentes tipos de fidelidad que presentan las adaptaciones de otras fuentes de textos? En nuestro caso supone una anécdota inicial aplicada a un contexto nuevo.

8. ¿Cómo las adaptaciones de televisión desafían los supuestos acerca de las diferencias formales e institucionales entre los textos verbales $\mathrm{y}$ audiovisuales que pueden ser pasados por alto en las discusiones que se limitan a la literatura y el cine? No compete pues no se trata de una adaptación televisiva.

9. ¿Cómo pueden, las adaptaciones basadas en textos fuente no literarios, o de no-ficción, ampliar la gama de estudios de adaptación al revelar la estrechez de miras de las teorías que restringen sus ejemplos sobre películas basadas en textos de ficción? En nuestro caso se trata de un texto de ficción, pero, paradójicamente, basado en una enfermedad real aunque extremadamente rara.

10. ¿Cómo son los modelos de adaptación, que asumen la primacía de los textos literarios impugnados por el fenómeno de las novelizaciones sobre la base de textos fuente en el cine? Nuestro modelo es de ampliación (más adelante se entenderá esta respuesta plenamente)

11.¿Cómo deben modificarse los modelos de análisis de las adaptaciones para aquellas películas que demuestren recurrir a otras fuentes, además de a sus textos fuentes iniciales, para tener en cuenta que algunos de ellos, tal vez, son más importantes que los textos fuente en la determinación de sus estrategias textuales? 'Memento' no recurre a otras fuentes de contenido, pero sí recurre al efecto género (negro en su caso) lo que la convierte en híbrido de fuentes pues el original no lo es.

12.Cuando las películas conscientemente plantean preguntas acerca de la propia condición de su adaptación, ¿qué implicaciones generales se ofrecen en los estudios de adaptación? En el presente estudio se 
imbrican efectos como el género y el largometraje.

13.¿Qué implicaciones se muestran como características frecuentes en las adaptaciones para generar teorías más amplias en el plano de la intertextualidad? 'Memento' se incluye dentro del lato mundo de las adaptaciones de relatos cortos al largometraje. En este caso se ha de estudiar la estructura narrativa (y los códigos visuales y de género).

14. ¿Cómo estudiar conceptos comúnmente tratados por los teóricos de la adaptación, como el cambio universal, cuando cruzan las fronteras nacionales y culturales? La historia de 'Memento' es extrapolable a cualquier país del ámbito occidental. Incluso se podría plantear en países in tradición detectivesca tanto en su narrativa como en su realidad del día a día (es decir, países sin tasa de criminalidad significativa).

15.¿Cómo deben mudar los modelos de adaptación para ajustarse a las novelas que formalmente y económicamente usurpan el lugar concedido tradicionalmente a las películas? Entendemos aquí que la película no afecta ni es afectada por su texto fuente.

Respondamos a estas cuestiones con el baremo que sea preciso en cada estudio, pues hay campo para abarcar casi todas las áreas literariocinematográficas. Lo que de fresco aporta este artículo es el análisis de los dos grandes trabajos sobre la adaptación que podemos resumir en sendas conclusiones:

1. Definir la adaptación como "la transferencia de un texto impreso en un género literario a la pelícu$l a$ " y la división de las adaptaciones en tres categorías: "cercanas, lejanas o intermedias", reflexiones debidas al trabajo de J. Desmond y P. Hawkes ${ }^{\text {iii }} \mathrm{y}$

2. Consignar las adaptaciones en el gradiente "literal, tradicional o radical", en una simbiosis de forma y fondo -en función del grado de libertad con la que se tratan los textos fuente, en guardia contra las herejías de la fidelidad, según el trabajo de Linda Constanzo Cahir ${ }^{\text {iv }}$. Trabajo éste que pretende "aumentar la habilidad con que sus lectores captan, aprecian, y se expresan sobre el cine, en concreto las películas que se basan en las fuentes $l i$ terarias", lo que lo convierte en una cita señera en el campo de la didáctica audiovisual.

Mantendremos aquí el uso de la palabra "adaptación" por ser más comúnmente aceptada y representar los contenidos semánticos que precisamos. 
Partamos para desarrollar nuestra labor presente de la base teórica de que el cine ya en 1911 es considerado como la (incipiente) séptima arte por derecho pleno (Ricciotto Canudo, 1911), complementando y completando (pues supone su unificación persistente, no como en el caso del teatro que es temporalmente volátil) a las otras seis clásicas, divididas entre las tres rítmicas: música, danza y literatura; y las otras tres plásticas: arquitectura, pintura y escultura.

Por tanto, nuestro punto de partida ha de ser formal ya que finca claro que el cine las puede asumir, aglutinar y perfeccionar, a las seis clásicas, a partir de su amalgama en un nuevo producto holístico, o fórmula de expresión, bien tildar como "artística" y, en el caso de las adaptaciones, incluso ayudar éstas a mejorar el original (cf. 'El silencio de los corderos' de Jonathan Demme en 1991 sobre novela homónima de Thomas Harris).

Sea como fuere coincidimos con Frago Pérez (2005, p. 5) cuando afirma que "si en algo están de acuerdo los académicos de la adaptación, desde Bluestone, es en negar la posibilidad de que una película adaptada sea absolutamente fiel al texto literario del que partió".

Este razonamiento se debe a la distinta sustancia de la expresión.
Por ello queremos aclarar que el concepto de literatura en 3-D (metáfora de "adaptación") no tendrá directa relación con el grado de eidetismo entre producto original -texto- y el derivado -película-, pero sí con su propia existencia y las sendas naturalezas formales de las obras.

\subsection{El efecto género}

Desarrollando la opción arquetípica que nos ofrece 'Memento' hemos de reparar en una barrera for$\mathrm{mal} / \mathrm{semántica} \mathrm{inicial:} \mathrm{el} \mathrm{género} \mathrm{y} \mathrm{su}$ escritura.

El género (concepto tan empíricamente sencillo como de muy compleja definición teórica) llamado "negro" ha sido, históricamente, uno de los que mejor se ha simbiotizado con los demás géneros, tanto literarios como cinematográficos. Tal es así que, incluso la ruptura, dentro de la misma trama, de la "sacrosanta" linealidad narrativa, basada en la definición aristotélica de tiempo secuencial "el número de movimientos respecto al antes y después, y su continuo" (Aristóteles, hacia 310 a. d. C.), a la que tradicionalmente la séptima arte se aferra, se quiebra, por vez primera, en una película ubicable en el subgénero de atracos dentro del género llamado "cine negro" (film noir, cinèma noir, e incluso, polard). Se trata de "Atraco perfecto' (Stanley Kubrick, 1956), la cual mostró la senda a otras películas 
también encuadradas en esta casa común de lo policíaco-detectivesconegro: 'Lemmy contra Alphaville' (Jean-Luc Godard, 1965), 'Reservoir dogs' y 'Pulp fiction' (Quentin Tarantino, 1993 y 1994)... Y entre ellas, analizaremos, por su rupturista novedad narrativa, 'Memento' (Christopher Nolan, 2000).

No se trata de generar "vueltas atrás", recurso clásico y multivalente donde los haya (como en la genial 'Juegos salvajes' -John McNaughton, 1998-, en la psicoanalítica 'Recuerda' Alfred Hitchcock, 1945-, en la filosófica '21 gramos' - González Iñárritu, 2003-, en la equívoca 'Sospechosos habituales' -Bryan Singer, 1995- o en la hilarante 'La vida por delante', de Fernando Fernán Gómez en 1958).

El relato corto primigenio es sencillo, formado por doce páginas ${ }^{\mathrm{v}}$ en las que el protagonista "habla" consigo mismo a través de notas que se deja, cuya autoría, dada su grave enfermedad justificación de la forma temporal de contar la historia-, desconoce. Nótese que en la película las notas son vistas directamente por lo que la inicial duda sobre si es un discurrir de conciencia, una voz en off o la aportación de un personaje que aún no ha aparecido no existe, algo que en el relato se va intuyendo y se descubre al final. Finalmente recurre a tatuajes indelebles con mensajes para sí mismo. Comien- za con el protagonista en un hospital del que huye para (imaginamos) matar a una persona que cree haber violado y matado a su esposa. La película comenzaría en la parte ubicada al final del relato.

'Memento' (locución latina, Recuerda, en español, alude a que su protagonista no puede recordar lo sucedido hace más de un minuto, pues sufre una enfermedad llamada "amnesia anterógrada") supone la transgresión ferozmente creativa del relato clásico literario y cinematográfico (y del género negro en particular), haciendo que el espectador trasmute, a su vez, en obligado co-autor, en una lectoescritura (Isidro Moreno, 2001, p. 112) que subraya la planteada por el propio Umberto Eco (Lector in fábula: la cooperación interpretativa en el texto narrativo, 1979). La trama detectivesca hace que el hilo conductor avance por mor de averiguar el propio espectador, quién es quién dentro de una historia policíaca clásica. En este punto queda claro que autores como Mínguez (1999) no aciertan al considerar que sólo en la literatura (frente al cine) el lector debe elaborar activamente el mensaje, ya que este tipo de cintas "desordenadas" obligan muy intensamente al lector a descodificar el mensaje a fin de poder entender la película. De hecho, los propios productores de la película dieron en til- 
darla, en tono medidamente publicitario, la "película-puzzle" (o película rompecabezas), término éste que autores como Warren Buckland han tomado para sus trabajos (2009) aun no traducidos al español. Más tarde han surgido páginas web con un montaje "clásico" del metraje.

El cine negro supone una elección de marco de referencia perfecta para mantener al público unido a la trama si se pretende una desconstrucción del hilo temporal narrativo -que imita el de la vida real, con un antes y un después a partir de un nexo causal apriorístico-, ya que el hecho de responder a preguntas básicas como espectadores (quién, qué, cómo, cuándo, por qué...) nos involucra en la lectoescritura habitualmente, pero en este caso se muestra como imprescindible ya que en el cine negro se responde siempre a preguntas nucleares, al más puro estilo detectivesco, (que es la base de la trama en este género), al romper la línea marcada en el siguiente esquema, hoy ya clásico, entre Público Real y Autor implícito. El espectador "hace apuestas" según le es dosificada la información sobre personajes, sus móviles, hechos y resolución final. La película no cierra su sentido, en este caso, con la ayuda del director ya que éste prefiere que las incógnitas del puzzle las solvente el lecto-autor, sin ofrecerle pistas nuevas, orientativas o definitivas.

No es imprescindible circunscribir al género y a sus reglas formales y semánticas este análisis, pero convendremos que las temáticas que presentan situaciones poco convencionales son más proclives a la mejora en la pantalla cinematográfica. Aquí halla carta de naturaleza el recurso a efectos especiales y a la generación de atmósferas especialmente visuales, muy del gusto de la ciencia-ficción.

Tal es así, que uno de los escritores de relatos cortos más aclamados del mundo, Philip K. Dick (1928-1982), autor exclusivo de obras de cienciaficción, ha sido quien más ha visto adaptadas al cine sus creaciones, sean éstas cortas o largas. Por citar las de más impacto en taquilla y crítica: 'Blade Runner' de Ridley Scott (1982) basada en su relato ¿Sueñan los androides con ovejas eléctricas?(1968), al que supera ampliamente; 'Desafío total' de Paul Verhoeven (1990) basada en Podemos recordarlo por Usted al por mayor (1966); 'Minority report' de Steven Spielberg (2002) basada en Informe de la minoría (1956), a la que supera; 'Screamers' de Christian Duguay (1995) basada en La segunda Variedad (1953) a la que supera; 'Next' de Lee Tamahori (2007) basada en El hombre dorado (1954) e 'Impostor' de Glary 
Fleder (2002) basada en el relato homónimo (1953). Sólo por citar algunas de las más señeras ya que el listado supera las 20 a fecha de hoy.

Existe, según Huber W., Keitel E. y Süss G., citados por Thomas Leitch ${ }^{\mathrm{vi}}$, un problema derivado de la alfabetización del espectador frente a "lo adaptado" sobre el concepto de lo que ellos dan en llamar "intermedialidad" como formadora de la alfabetización mediática. Este punto, y sin obviar su radicar importancia, merecería un estudio aparte del presente en el que enfocar concepto más derivados de la conducta del espectador que de la propia naturaleza narrativa.

\subsection{Narrativa cinematográfica}

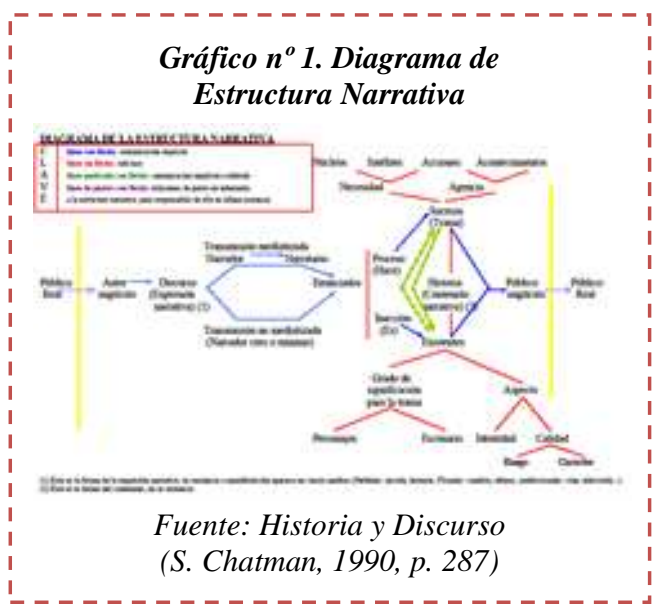

Es cimero entender, y en ello consiste la radical novedad de 'Memento', cómo los espectadores pasan a ser obligatoriamente "detectives" en esta pelí- cula, ya que se muestran tan desorientados como el mismo protagonista, y al producirse el estadio del espejo (Jacques Lacan, 2003) entre el espectador y el personaje, ambos deben responder a los mismos interrogantes. El protagonista sirve de narratario, bajo los más puros cánones del género negro (voz en off, vueltas atrás...) y así, además se logra que mediante este recurso estilístico la fase o estadio del espejo cristalice antes y más plenamente.

Desde los primeros años del cine, éste eligió para transmitir historias, la vía narrativa heredada de la literatura decimonónica, que a su vez, lo hiciera de la llamada clásica griega y latina. Inmanuel Kant nos enseñó que el espacio y el tiempo son inherentes al pensamiento humano o res cogitans de Descartes, en su Crítica de la razón pura (Inmanuel Kant, 1781), existan o no en la res extensa siguiendo la taxonomía del francés en su El discurso del método (René Descartes, 1637).

El relato cinematográfico ha intentado en variadas ocasiones contar historias desde un discurso no lineal, (aunque linealmente sea la forma en que vivimos), pero quizá no cómo recordamos, con constantes vueltas atrás y saltos adelante, de ahí que no podamos considerar ajenos a nuestra percepción tales recursos estilísticos, una vez vistos en la pantalla. 
No es de extrañar cómo Hollywood ideara, ya desde los primeros momentos del nacimiento de su balbuciente entramado empresarial audiovisual, recursos estéticos como montajes en paralelo (e incluso físicamente visuales, mediante pantallas divididas en planos de acciones distantes espacialmente pero coetáneas, de ahí su proyección simultánea), vueltas atrás, o analepsis (término acuñado por Gerard Genette, 1989), en las que sólo está interdicto el mentir (una salvedad, Hitchcock lo hizo en 'Pánico en la escena' (1950) y juró no volverlo a hacer pues producía animadversión en el público y una desorientación muy poco recomendable) y saltos adelante, o prolepsis, en los que el futuro se nos presenta como en un sueño o premonición, ya que de otra manera sería difícil poder aceptar esa visión de lo por venir (como en 'Dune' de David Lynch, 1984, en 'Dealers' de Colin Bucksey de 1989, en la trilogía de 'Mátrix' de los hermanos Wachowski, 1999-2003, o en 'Origen' del propio Christopher Nolan, 2010).

Nos centraremos aquí en los títulos que han recurrido a la descolocación de trazos de la historia lineal y reubicación en nuevo hilo constructor, como ejemplo de un intento de nueva narrativa: Convenimos como cimeras 'Atraco perfecto' (Kubrick, 1956), 'Pulp fiction' (Tarantino, 1994), '12 monos' (Gilliam, 1995), 'Nirvana' (Salvatores, 1997), '21 gramos' (G. Iñárritu, 2003) y 'Memento' (C. Nolan, 2000).

Una vez analizado este esquema, tomamos a Graciela Reyes, en su Polífonía textual: La citación en el relato literario (Reyes, 1984), como guía introductora en los campos señeros de la narrativa que sirven de punto de enfoque del prisma del autor, sus funciones y recursos y que constituyen el alma mater de la creación audiovisual, por lo que dedicaremos una reflexión previa a su desarrollo antes de proseguir con otros necesarios conceptos narrativos.

En el discurso literario hay un hablante o sujeto de enunciación primero, básico, el narrador autorizado, pero muchos enunciadores a los que se atribuyen discursos, y muchos locutores a los que momentánea, caprichosa o consistentemente se deja hablar allí donde la narración progresa como escena. Muchas son, pues, las voces de la narración asumidas o reproducidas por el narrador, y muchas las voces que el narrador cita, re-cita, suscita. En esta algarabía de discursos, por orígenes diferentes que constituyen la sustancia misma del relato, no siempre es fácil distinguir la voz fundadora, y en principio veraz, del narrador. Pero tal distinción es in- 
dispensable: si no sabemos quién lo dice, no sabemos si sucedió, o si es una alucinación, un sueño, un recuerdo, una fábula falsa en el marco de la fábula verdadera de la ficción.

El narrador, con sus afirmaciones descriptivas y narrativas, crea el sistema de proposiciones que constituyen el mundo «cierto» de la ficción, del cuento o de la novela. Su relato configura un interlocutor, el narratario que ha de tomar al pie de la letra las afirmaciones del narrador. El lector de carne y hueso que pone en el lugar del narratario, no lee la literatura como literatura; esa participación creativa comienza con la suspensión de incredulidad de la que ya nos habló Coleridge. ${ }^{\text {vii }}$ (G. Reyes, 1984, p. 67)

Esta suspensión de la incredulidad ha servido no sólo de elemento de estudio para analistas literarios, sino que incluso se explicita en uno de los diálogos de la película 'Instinto Básico' viiii (1992) de Paul Verhoeven, cuya protagonista femenina Catherine Tramell, encarnada por Sharon Stone, una universitaria doblemente licenciada en literatura y psicología, quien aplica sus conocimientos en tanto escritora de libros que se convierten en superventas, basa el éxito de sus novelas en la correcta suspensión de la incredulidad en las conciencias y consciencias de los lectores a los que atrapa como una araña a las moscas en su telarañarelato.

El cine, por lo tanto, nos miente hasta donde estamos dispuestos a creerle.

El caso de 'Juegos salvajes' (John McNaughton, 1998), es paroxístico, pues nos explica las elipsis informativas (donde el espectador puede entender que se ha jugado con él) tras finalizar la película linealmente, mediante cortes con las secuencias "escamoteadas al espectador" durante el pase de los títulos de crédito y que le permiten aceptar como lógico el desenlace mostrado.

El autor clásico, en sus obras, va a adoptar este papel de narrador impersonal omnisciente, sin atender a ningún otro tipo de narrador dentro de la ficción. La voz en off (aspecto focalizador en el que el personaje se corresponde con el narrador) se emplea sólo como solución narrativa. El cine negro siempre se ha decantado por este tipo de recurso creativo ya que el discurrir de la conciencia (al estilo de Marcel Proust en su amplísima En busca del tiempo perdido, 1908-1922) del protagonista es la mejor forma de crear complicidad y resolver arduas explicaciones visuales, que corren el riesgo de no ser plenamente entendidas por el público. En 'Memento' esta estrategia narrativa es básica y está plenamente justificada por su grave enfermedad. 
Podríamos decir que se trata de un recurso diegético, pese a su "anaturalidad" temporal desde el rasero de una persona sana.

Sea Mieke Bal con su esquema sobre el valor de la verdad (lo que permite ahondar en lo verosímil frente a lo verdadero y sus posibilidades narrativas), quien nos clarifique el enfoque final sobre las posibilidades habidas:

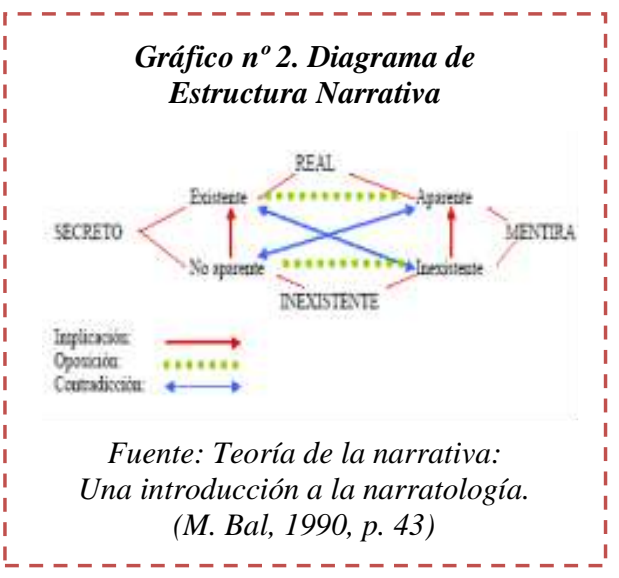

Los ejemplos cinematográficos son escasos pero intensos en este punto. Así Alfred Hitchcock ix en 'Pánico en la escena' (1950) ta-atrás" falsa en los recuerdos de la protagonista femenina. Los resultados ante el público le desaconsejaron volver a intentar mentir (o sea, adornar la verdad), lo cual nos lleva a una concepción de narrador como "sumo pontifice" garante de la veracidad de lo contado que no debemos confundir con la capacidad de cumplimiento de los hechos mostrados en el mundo real.

Si bien no se trata de una mentira stricto sensu, la obra laureada con el Óscar a la mejor película, entre otros galardones, en 1973, 'El Golpe ${ }^{\text {xi }}$ de George Roy Hill, basa su sorpresa final en el encubrimiento de una parte crucial de la información que posee el directornarrador de la cinta (con una pequeña trampa previa -el personaje de Salino). El director David Mamet, en su ' $\mathrm{Ca}$ sa de juegos 'xii (1987), pretendió imitar el tono de embaucamiento al espectador que ya mostrara en 'El Golpe' aunque sin llegar al nivel de ésta.

Wayne Booth ${ }^{\text {xiii }}$ (1983) acuñó el término "Narrador poco fiable" que de momento estacionaremos en beneficio de la figura del narrador como sustentador de un mundo cierto dentro de esa ficción consensuada con el espectadorlector-receptor. Este narrador crea una serie o sistema de proposiciones con sus afirmaciones descriptivas y narrativas que sirven para delimitar lo cierto de lo que no lo es, y en general lo que sí existe (siempre mostrado) de lo que no (lo no mostrado, es decir, la información que no ha sido dada y que nunca lo será ya que no tiene carta de naturaleza en este universo de lo ficcional de la película concreta). El espectador-lector-receptor que no se ubica en el lugar del narratario no afronta la literatura en cuanto literatura 
(la citada "suspensión de incredulidad"). En 'Memento' la escasa o nula fiablidad del narrador (o sea, "de quien cuenta la historia") se deriva, por una parte, de los recuerdos borrosos (o propensos a la falsedad o incompletitud dada la enfermedad sufrida) del protagonista y las pistas que el espectador estudia a partir de su enunciación y punto de vista, sea veraz o falsa, y, por otra parte, de la información que los demás personajes emiten (es decir de todos menos del protagonista) ya que ellos crean historias -no sabemos como espectadores si verdaderas o falsas- para engañar o ayudar al protagonista sea mediante diálogos o mediante acciones mostradas al espectador. Este recurso a varios narratarios mentirosos-fiables es la base de la trama de la película.

En los casos que nos ocupan, las líneas temporales "construidas" a imagen y semejanza de nuestro pensamiento se rompen en tramas argumentales simples y que sirven para explicar unas a otras, dejando para el final la trama inicial que explica las anteriormente vistas, pero posteriores en el tiempo, como si de una gigantesca vuelta atrás se tratara, con un narrador no sólo omnisciente, sino fuera del tiempo humano, y que nos muestra por moviola la situación de los personajes, los hechos y sus interrelaciones.
Examinemos, pues, la estructura del acto narrativo ficticio, en el cual se comunican realmente narrador y narratario.

En cuanto al narrador, es preciso distinguir el relato en primera persona, en el cual el narrador es personaje o testigo o se muestra como Deus exmachina muy del gusto del neorrealismo italiano (recordemos los casos similares en la cinematografía de España 'Bienvenido Mister Marshall' 1952-, 'Calabuch' -1956- o 'Calle Mayor' -1956-) y el relato en tercera persona, en el cual el narrador cuenta desde fuera, sin participar en el mundo narrado, es decir, sin mostrarse gramaticalmente como narrador ${ }^{\mathrm{xiv}}$. 'Memento' opta por esta construcción del relato, tan al gusto del género negro, pero con la peculiaridad originalísima, de tener que construir un yo narrador explícito a cada secuencia dada la falta de creación de memoria a medio y largo plazo del protagonista (en la película, el protagonista nos cuenta en voz alta lo que le está pasando y lo que va deduciendo, también lo que escribe en sus tatuajes personales a fin de que perduren más que los simples papeles de notas, así como oímos su conciencia con las vueltas atrás que sirven para ubicar al espectador en las claves de la historia que está, como si fuera un detective, desentrañando). El director opta aquí por un recurso en exclu- 
siva propio del lenguaje cinematográfico (imposible en el literario) que es la mezcla del color -la realidad actualy el blanco y negro -los recuerdos-.

Por lo tanto, nos hallamos ante una narración considerada ya homodiegética ya hetereodiegética, pero siempre en función de la historia y la implicación pretendida con el lectoautor, que es quien descodifica para entender la trama, pues no se le van a ofrecer pistas sobre la veracidad de lo visto u oído, sino que se le van a presentar diálogos y situaciones que él debe encasillar dentro de lo verosímil (pues produce hipótesis), veraz (que produce asertos) y mentira (lo que hace que las hipótesis iniciales, sobre quién es quién y qué es verdad, se refuten). El personaje (dada su enfermedad y el espectador sufren la misma angustia sobre lo correcto de los actos reflejados que acomete el protagonista). Esto nos lleva a coincidir con el aserto de que la focalización es, en resumen, voz y perspectiva como afirmara Genette (1972 y 1983) y apostilla Graciela Reyes (G. Reyes, 1984, p. 100).

Caso especial supone 'Rashomon' de Akira Kurosawa (1950), también una adaptación de dos cuentos cortos, Rashomon (1915) y En el bosque (entre el 1915 y 1919) de Ryunosuke Akutagawa. Esta cinta disonante con las narrativas imperantes en occidente (y también en oriente) supone un caso especial pues:

Una de las cuestiones más interesantes de 'Rashomon' y que llamó desde el principio la atención de la crítica especializada es cómo estaba contada la historia. Es concreto, la experimentación del tiempo cinematográfico y de la perspectiva. En la década de los 50, este filme se asoció principalmente con la más arriesgada de las vanguardias por el uso revolucionario de una narración basada en múltiples enfoques. Estaba contada a través de varios flashbacks que ponían en evidencia cómo las particulares miradas de los personajes sobre un mismo hecho no contenían la verdad de lo ocurrido. Es decir, se ponía en tela de juicio lo mostrado visualmente por la cámara ya que los relatos contados estaban manipulados por los intereses de sus emisores. (Grandío-Pérez, 2010, p. 3)

Desmond y Hawkes (2005) también se centran en analizar las formas de Akira Kurosawa Rashomon (1950), a las que suman la película Blow-Up (1966) de Michelangelo Antonioni. Se centran en valorar los capítulos necesarios en la adaptación de novelas, cuentos y obras de teatro lo que se complementa con los análisis de los desafíos de la adaptación de la no-ficción, de los docu- 
dramas y de los textos literarios, llegando incluso a los dibujos animados

Es decir, ya en 1950 se planteaba como objetos de juego creativo tanto el punto de vista múltiple (no la cámara subjetiva sólo) y la dosificación de la información a partir de intereses que conllevan verdad o mentira para que sea de nuevo el espectador quien tome partido y elabore en su mente la historia real frente a las historias posibles. De esta manera, por descarte de lo imposible o lo desautorizado por otras fuentes ajenas a la que emite el mensaje que se está recibiendo, el espectador puede entresacar lo que realmente ha sucedido. Asimismo los personajes se retratan ante él de manera inequívoca atendiendo a la información que ofrecen según las dicotomías: veraz o no, interesada o no.

Desmond y Hawks (2005) huyen aquí de las taxonomías. Aprovechamos para citar su recurso al concepto de "fidelidad", que, según ellos: "Es utilizado no como un término evaluativo que mide el mérito de películas, sino como un término descriptivo que permite la discusión de la relación entre los dos trabajos [relacionados según los criterios] mantener, eliminar o añadir".

Por este motivo convenimos en añadir a nuestro postulado el concepto "literatura en 3-D" que no pretende ser sino una metáfora de la palabra adaptación. $\mathrm{Su}$ grado de fidelidad hará que nos hallemos ante un tipo u otro de "cinematografización" (sit venia verbis) o 3-D (alusivo al paso de palabras a imágenes) más o menos logrado, sin que en sí, este grado suponga una calidad mayor o menor, sino una mayor o menor propiedad al hablar del concepto 3-D.

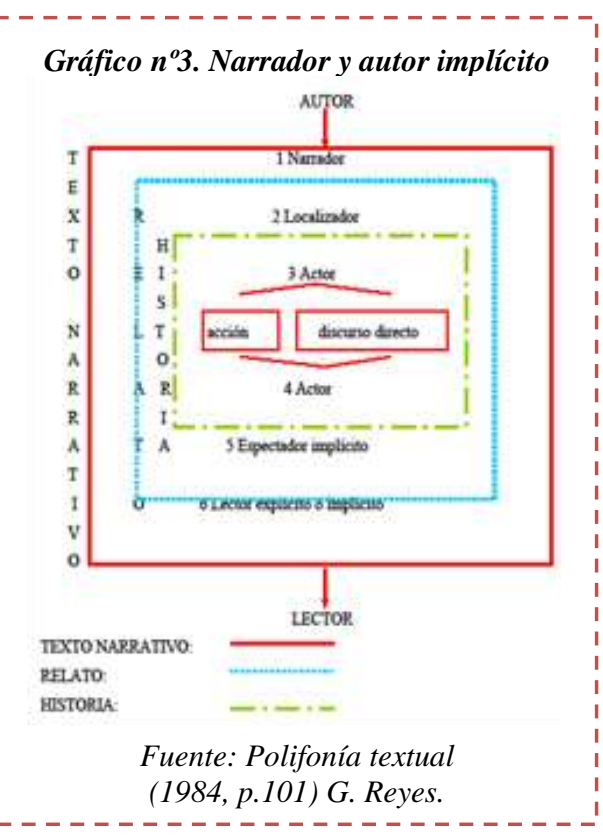

Este esquema nos ubica también en el campo de las intenciones que se puedan o no plantear en la mente creadora y su consecución en al campo de los logros o fallos, lo que nos remite, de nuevo, a una opción o toma de postura personal sobre el perfil del receptor según el emisor.

El espectador percibe al autor implícito en la medida en que es capaz de 
desdoblarse y adoptar el papel de espectador del autor y narratario del narrador (este desdoblamiento, en el campo de la lingüística y la literatura, ha sido denominado lectura icónica o autorreflexiva). 'Memento' supone acentuar esa bilocación espectatorial para involucrarla en la trama (en ello reside su originalidad).

El narratario es un autor implícito, es decir, un emisor-hablante del texto, y en el caso de 'Memento' es quien lleva el hilo conductor especialmente mediante vueltas atrás, cámaras psicológicas o subjetivas y voz en off. El director ayuda al espectador subrayando mediante el recurso al blanco y negro o color de las secuencias, el carácter actual o de recuerdo de las imágenes mostradas. No es un autor mentiroso que juega con la dosificación de la información falseándola (algo de lo que se puede acusar a ' $E l$ sexto senti$d o$ ' de M. Night Shyamalan -1999- o 'Los otros' de Alejandro Amenábar 2001-) y esto hace que el pacto de credulidad se mantenga sin estridencias.

Este estilo de transgresiones a la linealidad de la temporalidad cinematográfica se da en las citadas cintas 'Atraco perfecto' (1956) de Stanley Kubrick y en las obras de Quentin Tarantino influidas por la anterior, como 'Reservoir dogs' (1993) y muy especialmente en su aclamada 'Pulp fiction' (1994), en la que el mafioso personaje de Vicent Vega (John Travolta) "resucita" dentro de la película, ya que ésta se nos narra como si de varias secuencias desordenadas se tratara, pero con un hilo argumental común en el que confluyen varios hilos más débiles.

El uso de cámaras subjetivas ha sido explotado por géneros como el terror o el negro, sin olvidar el religioso ${ }^{\mathrm{xv}}$, $\mathrm{y}$ que incluso hay películas que basan algún efecto cómico en este juego ${ }^{\mathrm{xvi}}$, pero en 'Memento' sólo sirven para focalizar la información, es decir, matizar lo que se sabe por parte de un personaje -porque se ve- y lo que no.

En 'Atraco perfecto' (1956) de Stanley Kubrick la historia se nos cuenta desde el punto de vista que poseen varios protagonistas, con lo que tenemos una serie de vueltas atrás muy marcadas y unos ángulos físicos de visión distintos sobre las mismas acciones. En ' $\mathrm{La}$ vida por delante ${ }^{11}$ (Fernando Fernán Gómez, 1958) sucede lo mismo. Quentin Tarantino en sus películas recurre a este modo narrativo con prodigalidad, como en sus 'Reservoir dogs' (1993) o 'Pulp fiction' (1995), en las que el orden narrativo "habitual" se deslinealiza con vueltas atrás, capítulos estanco (en 'Pulp fiction' hay varios capítulos encabezados por su título propio, al más puro estilo de cualquier novela «de ahí el título "Pulp fiction" "Novela de bolsillo o barata", en es- 
pañol-», que crea sus porqués en un oscuro pasado que se nos muestra en capítulos satélites) y puntos de vista diversos sobre las mismas acciones, con lo que se produce la paradoja de que sabemos que un personaje ha muerto y es resucitado en el siguiente capítulo porque éste, cronológicamente, era anterior (lógicamente) a la fecha de su muerte por asesinato de un personaje que también altera con su presencia esa linealidad subjetiva de percepción de la vida.

De Felipe y Gómez (2008) $)^{\text {xvii }}$ presentan una reflexión profunda en su libro ensayo Adaptación, en el que se concentran una serie de elementos canónicos que todas las adaptaciones han de presentar. Por prolijo, no podemos elaborar aquí ni tan siquiera un esquema dada la escasez de espacio y la profundidad del trabajo. Baste con centrar el punto fuerte que afecta al presente artículo, la imperiosa necesidad de analizar el guion como base inicial para entender la naturaleza de la adaptación como esencial paso intermedio. 'Memento' supone una mudanza drástica entre el texto fuente y la película resultante. Entre ellos existe un paso intermedio: el guión que sirve para allanar las brusquedades del camino de la traslación. Es un concepto importante que podría ser, en sí, objeto de un estudio pormenorizado aparte.
Por concluir este repaso a la construcción/desconstrucción del relato clásico cinematográfico recapitulemos sobre la trilogía citada como ejemplo de discurso de nueva linealidad:

Motivación creativa: Crear extrañeza en el espectador y que trate de cerrar el sentido de varias de las situaciones presentadas y sus causas. Arquetípico el caso del maletín de 'Pulp fiction' cuyo brillante contenido nunca se nos muestra.

Aportación narrativa: Cambio de concepto de narrador omnisciente en tercera persona o impersonal. Ahora está fuera del tiempo también.

\section{3. 'Memento': ruptura de la linealidad}

Un ejemplo claro de esto y que obliga a reestructurar completamente la linealidad del relato (diégesis) se da en 'Memento' como generador de nuevas estructuras relatuales:

La película comienza contando el final de la historia: Teddy muere a manos del protagonista, Leonard (recordemos que se trata de una cinta de género negro). El narratario es Leonard (con voz en off incluida, típica del género negro) pues a través de sus ojos llegamos a saber quién es quién en la película y los porqués de las situaciones inconexas para el espectador ya que la lógica lineal (desde el antes hasta el 
después) se esfuma. Por ejemplo, vemos una ventanilla rota de un coche y al cabo de 30 minutos de película entendemos cómo sucedió esa rotura. La particularidad, entendida como justificación de la estructura narrativa se debe a que Leonard sufre una enfermedad llamada "pérdida de la memoria a corto plazo" (amnesia anterógrada) por lo que ha de anotar y fotografiar todo lo que le va pasando a fin de no perderse en el mundo que le rodea, el cual se reconstruye "hacia atrás" a cada momento mediante notas y tatuajes. El "Mac Guffin" hitchcockiano consiste en buscar a la persona que mató a su mujer y que le provocó traumáticamente la enfermedad de la memoria.

Ahora intentemos recrear la historia a través de los límites que constriñen los recuerdos posibles del último minuto vivido.

El siguiente esquema se nos presenta caleidoscópicamente durante toda la película de manera que se resuelven los problemas de dosificación de información mediante una estudiada redundancia que nos permite, a la vez, conocer a los personajes:

1. Anécdota 1 (cita, charla, pelea, persecución...) $\rightarrow$

2. Elemento nuevo para que más adelante sea explicado (nuevo coche, ventanilla rota....) en especial escri- tura de textos en las fotografías Polaroid que explican la relación de Leonard con la imagen (mi coche, nombre de la persona que aparece, me ayudará por compasión, no te creas sus mentiras...) $\rightarrow$

3. Pre-fin de la anécdota $\rightarrow$

4. Paso a una historia en Blanco y negro similar a la suya en paralelo (una especie de historia de su enfermedad según le había sucedido a otra persona que él conoció) mientras habla por teléfono con una especie de "garganta profunda" de 'Todos los hombres del Presidente' (Alan J. Pakula, 1976). Sirve de enganche y separación a la vez. $\rightarrow$

5. Fin de la anécdota $1 \rightarrow$

6. Comienza la anécdota 2 que tuvo lugar cronológicamente justo antes de la anécdota 1 y su fin enlaza (pues coincide plano a plano) con el comienzo de la anécdota 1 que ya viéramos minutos antes.

Es una historia en bucle ad infinitum. Simple pero muy efectivo. En cuanto a la historia, a cada nueva anécdota, la relación de los personajes varía.

Recordemos que en el relato corto primigenio, sólo hay una voz del narratario (la tercera persona que describe ámbitos o narra acciones) y la $v o z$ en off que representa el texto que el protagonista lee en las sucesivas notas. 
Personajes: Se nos presentan en relaciones abruptas como en 'Memento', o en resurrecciones e incluso como focalizadores o mostradores de puntos de vista distintos sobre los mismos hechos, como en 'Atraco perfecto'.

Por ello, el juego con el tiempo es clave de la trama planteada por ' $M e$ mento' (ambos tiempos posibles, el real o duración de la cinta y el narrado, lo que nos lleva a un concepto psicológico de percepción) ya que el protagonista ha de recordar mediante rótulos, fotos instantáneas, tatuajes y notas quién es quién en su vida mientras trata de resolver un asesinato y por ello se cuenta la historia hacia atrás, ya que pretende recordar qué pasó (verdadera obsesión del protagonista que quiere saber quién es y qué le ha pasado a su esposa, y que no puede obtener respuestas dada su enfermedad, justificante de la trama y su "novedosa alinealidad"). Es un argumento inteligente que pretende justificar filosóficamente esta forma de contar el paso del tiempo tan ajena a nuestra percepción.

Gracias a esta manipulación temporal que dosifica información, desde varios puntos de vista, 'Memento' se juega con el ser y el parecer de los personajes los cuales a cada nueva vuelta de tuerca informativa (anécdota) van cambiando de buenos a malos y viceversa. Se busca despistar al espectador para que genere sus propias historias hipótesis y monte su película a cada paso. Esta fórmula fue muy trabajada en relatos novelescos de los años 80 del siglo XX, en los que el lector creaba su propio discurrir de los hechos con las opciones que el autor le permitía al final de cada minicapítulo con decisiones bi o tri-cotómicas y que le llevaban, según lo elegido, a una página o a otra. Se trataba de novelas de multilectura que no tenían sentido si se leían sus páginas siguiendo el orden numérico de las mismas, pues los saltos de acción (e incluso resurrecciones, nuevos personajes, etc.) eran constantes y no hilvanados. Un intento de multiposibilidad "en tiempo real" fue 'Dos vidas en un instante' (Peter Howitt, 1998), película que planteaba dos futuros-realidades paralelos en los que la protagonista cambiaba radicalmente de vida en ambos, tan sólo separados por coger o no a tiempo un tren de vuelta a casa. No hay que confundir esta bilinealidad (no simultánea sino disyuntiva) con la división de la pantalla en varias vistas sea para reproducir una conferencia telefónica (con múltiples ejemplos), sea una situación múltiple coetánea (compra de acciones por parte de varios "tiburones bursátiles" en la película 'Wall Street' de Oliver Stone, 1988) o dos puntos de vista sobre una acción convergente (' $E l$ estrangulador de Boston' de Richard 
Fleischer, 1968, también película detectivesca).

La literatura fue la precursora con novelas (generalmente infantiles $o$ juveniles) en las que el propio lector elegía la deriva de la historia al final de cada capítulo sobre alguna de las opciones que le ofrecía el autor y así, dependiendo de ésta, pasar a un capítulo u otro de los que conforman el libro, que nunca podía ser leído de manera lineal ya que los capítulos se paginan linealmente pero son excluyentes entre sí.

En el caso de '21 gramos' (2003), en la que se alude a la existencia o no del alma (21 gramos sería su peso según la leyenda pseudo-científica de que una persona, en el momento en que expira, pierde esa cantidad de peso), se pretende reconstruir una vida y unos porqués vitales a partir de una situación límite del protagonista (la postración), situación parecida a la sufrida por el protagonista de 'Memento' dada su enfermedad.

Tanto Efrén Cuevas (2005) como la página web oficial de la película ' $M e$ mento', (www.otnemem.com) (nótese la sutil ironía al colocar el título de la cinta al revés, imitando un orden lineal inverso al esperado) coinciden en que el esquema de la sucesión de las secuencias que conforman la película se corresponde con el siguiente:

\section{Gráfico $n^{\circ} 4$. Esquema temporal de la narración}

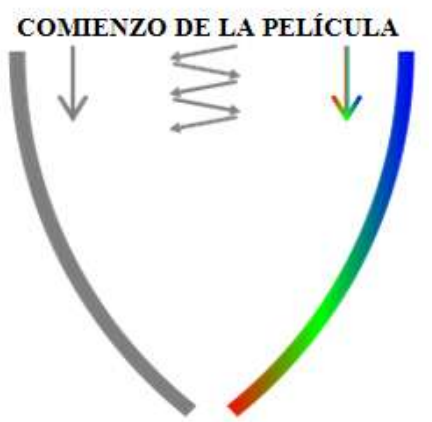

FIN DE LA PELÍCULA

Fuente: Página web oficial de la película www.otnemem.com

Incluso en el DVD se plantea un montaje más linealmente clásico para facilitar su comprensión entre las secuencias en blanco y negro que son recuerdos (a la izquierda en este esquema) y las de color que es la realidad actual (a la derecha) y su entrelazado temporal. De hecho se comienza por los títulos de crédito finales.

Para poder marcar este tipo de montaje como especial, podemos citar el caso, entre las numerosas opciones que se nos presentan y a las que este título aquí representa, de 'Muerte en Venecia' de Lucino Visconti (1971) En esta cinta hallamos que "El uso de los flashbacks y de los flashfowards marca la película de 'Muerte en Venecia'. El autor pasa a ellos como pasaría a cualquier otra escena, al corte y sin dar ningún tipo de señal al espectador" 
(Felipe-López, 2006, p. 14). Esta asignificación, allende la clásica funcionalidad narrativa, hace que 'Memento' brille por su novedosa intencionalidad del montaje 'alineal'.

Por ello, queda claro que este nuevo pulso narrativo ante el espectador supone una vuelta de tuerca en la reinvención-hibridación de géneros $\mathrm{y}$, en nuestro caso en el del cine negro, otrora clásico y hoy cinematográfico en auge.

Los planteamientos narrativos cinematográficos han ayudado a dotar a este tipo de historias cortas de nuevas posibilidades narrativas no sólo derivadas del lenguaje audiovisual (pues el esquema anterior sería imposible en una novela ya que el lector se perdería en el desarrollo) sino también de una nueva dimensión (como si de un 3-D se tratara) ya que las licencias basadas en las identificaciones (fase de espejo según Lacan) se pueden producir de manera más directa y el desarrollo de las tramas complejizarse al separarse de la esclavitud de las detalladas descripciones resueltas de manera deíctica y la profusión de guiños de los personajes hacia el espectador (como el intento de ganar la credibilidad del espectador entre el protagonista y el policía en nuestro ejemplo) para ahondar más aún en la verosimilitud, que no veracidad, de la séptima arte. Este concepto de 3-D alude a lo que todo espectador entiende como aportación del cine a la obra escrita. Se trata de una metáfora que podrá ser captada en su plenitud cuando el espectador haya sido previamente lector y pueda entender si esa "tercera dimensión" que ofrece el trampantojo del cine es acorde o no con la prometida en las páginas y remedada por su propia imaginación de lecto-autor.

\section{4. 'Memento': como estrategia discursiva}

Desmond y Hawkes (2005) muestran cómo sólo existen, en su modelo, tres estrategias de adaptación.

1. Estrategia de concentración: Película que presenta una historia casi línea por línea antes de romper en una dirección completamente nueva pasados los momentos de identidad con el texto, como 'Forajidos' de Robert Siodmak (1946) sobre texto de Ernest Hemingway.

2. Estrategia de entrelazamiento: Película que conserva los elementos principales de la historia inicialmente, pero sin concentrarlos pues los presenta dispersos por todo el metraje, entrelazándose mediante invenciones o ampliaciones sobre los ya existentes, como El nadador de Frank Perry (1968).

3. Estrategia del punto de salida: Ejemplificada por la adaptación que Chistopher Nolan realiza del 
relato Memento Mori, escrito por su hermano Jonathan en 2001. Se trata de partir desde los elementos narrativos de la historia corta e inventar una nueva historia, pero basada en los elementos antecedentes.
4. Después de esbozar estos tres enfoques convendremos en que disgregar historia de relato es la mayor aportación de lo cinematográfico a lo literario. 'Memento' supone el mejor ejemplo.

\section{Conclusiones}

Los relatos cortos han supuesto para la cinematografía un filón de inspiración a los guionistas quienes han aprovechado las amplias posibilidades que se les ofrecían fuera de los corsés de los relatos amplios, para generar algunos de los títulos más emblemáticos dentro de los dos géneros que más y mejor se han visto afectados por estas traslaciones de lenguaje: el de ciencia ficción y el negro. En el estudio de caso aplicado a 'Memento', hemos podido desbrozar en el plano de la forma del contenido cómo la historia y el discurso podían transgredir el lineal continuo del transcurrir del tiempo para conformar una de las películas formalmente más rupturistas de la historia del cine mundial. El género de cine negro (junto con el de ciencia-ficción) ha sido finalmente mostrado como muy especialmente apto para este tipo de desconstrucciones mediante los numerosos ejemplos propuestos. Finalmente ha quedado demostrado que las posibilidades narrativas propias del lenguaje cinematográfico mejoran las narraciones que basan su carta de naturaleza en una espacial relación entre el autor y el "lector-espectador", vehiculando historias complejas con una facilidad y tipos de codificaciones (auditivas, textuales e icónicas, por citar sólo las principales) imposibles en la literatura. En especial la ruptura de la linealidad narrativa encuentra su mejor aliado en el cine, superando las posibilidades de los relatos que adapta. 


\section{Referencias}

Aristóteles de Estagira (1974 [hacia 310 a. d. C.]). Poética. (Traducción de García-Yebra, V.). Madrid: Gredos.

Bal, M. (1990). Teoría de la narrativa: una introducción a la narratología. Madrid: Cátedra.

Booth, W. (1974 [1971]). La retórica de la ficción. Barcelona: Bosh.

Cahir, L. C. (2006). Literature into Film: Theory and Practical Approaches. Jefferson, Carolina del Norte: McFarland.

Caldevilla-Domínguez, D. (2005). El sello Spielberg. Madrid: Vision Net.

Canudo, R. (2006 [1911]). Manifiesto de las siete artes. Disponible en: www.cinefagos.net/ index.php?option $=$ com_content $\&$ view $=$ article \&id=436:manifiesto-de-las-siete-artes\&catid $=30$ :documentos \&Itemid=60. Consultado el 01/09/2011.

Clarke, A. C. (1980 [1948]). El centinela, en Wynorski, J. (Coord) Vinieron del espacio exterior. Madrid: Martínez Roca.

Cuevas, E. (2005). Christopher Nolan visto desde Gerard Genette: análisis narratológico de Memento, en Revista ZER n ${ }^{\circ}$ 18: 183-198. Disponible en: www.ehu.es/ojs/index.php/Zer/ article/view/3932/3546. Consultado el 12/09/2011.

Cahtman, S. (1990). Historia y discurso. Madrid: Taurus. Pág. 287.

De Felipe, F. \& Gómez, I. (2008). Adaptación. Barcelona: Blanquerna.

Descartes, R. (2001 [1636]). El discurso del método. Disponible en: www.weblioteca.com .ar/occidental/delmetodo.pdf. Consultado el 18/09/2011.

Desmond, J. M. \& Hawkes, P. (2005). Adaptation: Studying Film and Literature. Nueva York: McGraw-Hill.
Eco, U. (1993 [1979]). Lector in fábula: la cooperación interpretativa en el texto narrativo. ( $3^{a}$ edición) Madrid: Lumen.

Felipe-López, A. R. (2006). Reflexión sobre el cine de Visconti desde el estudio de su narrativa audiovisual, en Revista de la SEECI, $\mathrm{n}^{\circ} 13$. p. 14. Disponible en: www.ucm.es/info/seeci /Numeros/Numero 13/InicioN13.html. Consultado el 19/09/2011.

Fernández, L. M. (2000). Don Juan en el cine español: hacia una teoría de la recreación fílmica. Santiago de Compostela: Universidad de Santiago.

Frago-Pérez, M. (2005). Reflxiones sobre la adaptación cinematográfica desde la perspectiva iconológica, en Revista Comunicación y sociedad, $\mathrm{n}^{\circ}$ 2. Disponible en: www.unav.es /fcom/comunicacionysociedad/es/articulo.php? art_id=71. Consultado el 10/09/2011.

Genette, G. (1989 [1972]). Discurso del relato. Barcelona: Lumen.

Genette, G. (1998 [1983]). Nuevo discurso del relato. Madrid: Cátedra.

Gimferrer, P. (1999). Cine y literatura. Barcelona: Seix Barral.

Grandío-Pérez, M. M. (2010). Tiempo y perspectiva en la película de Rashomon de Akira Kurosawa, en Revista de Comunicación Vivat Academia, $\mathrm{n}^{\circ}$ 111. Disponible en: $\underline{w w w . u c m . e s}$ /info/vivataca/numeros/n111/PDFs/Grandiocop p.pdf. Consultado el 01/09/2011.

Huber, W.; Keitel, E. \& Süss, G. (2007). Intermedialities. Trier: Editorial científica Trier.

Kant, I. (2005 [1781]). Crítica de la razón pura. Madrid: Taurus.

Lacan, J. (2003). La transferencia. Buenos Aires: Paidós. 
Leitch, T. (2008). Adaptation Studies at a Crossroads, en revista Adaptation. Disponible en: http://adaptation.oxfordjournals.org/content /1/1/63.full. Consultado el 04/07/2012

Mínguez, N. (1998). La novela y el cine: análisis comparado de dos discursos narrativos. Valencia: La Mirada.

Moreno, I. (2001). Genoma digital en Revista Anàlisi, $\mathrm{n}^{\mathrm{o}}$ 27. Pág. 112. Disponible en: www.bib.uab.es/pub/analisi/021121 75n27p101.pdf. Consultado el 15/09/2011.

Nolan, J. (2001). Memento mori. Disponible en: $\quad$ www.maitrianland.com/textos/memento moritrad.doc. Consultado el 05/09/2011.

Ravinowitz, P. (1977). Verdad en la ficción: Una re-examen de audiencias, en Revista Critical Inquiry. Chicago University Press. Págs. 67-76.
Reyes, G. (1984). Polifonía textual. Madrid: Gredos. Pág. 67 y ss. y 100 y 101.

Sánchez-Noriega, J. L. (2000). De la literatura al cine. Teoría y análisis de las adaptaciones. Barcelona: Paidós.

Sánchez-Noriega, J. L. (2000). Las adaptaciones literarias al cine: un debate permanente, en Revista Comunicar, $n^{\circ}$ 17. Págs. 65-69. Disponible en: http://redalyc.uaemex.mx/redalyc/ pdf/158/15801709.pdf. Consultado el $10 / 09 / 2011$.

Villanueva, D. (1999). Los inicios del relato en la literatura y en el cine, en Castro-De Paz, J. L.; Couto, P. \& Paz, J. M. (Coords.) Cien años de cine. Historia, teoría y análisis del texto fílmico. Madrid: Visor.

\section{Cita de este artículo}

Caldevilla Domínguez, D. (2012) El relato corto en el cine. Literatura en 3-D: 'Memento' de Christopher Nolan (2000). Las adaptaciones literarias en la gran pantalla: una cuestión. Icono14 10(2), 168-195, doi: 10.7195/ri14.v10i2.414

\section{NOTAS}

${ }^{\mathrm{i}}$ Disponible en: www.apocatastasis.com/el-centinela-the-sentinel-arthur-clarke.php\#axzz1suWo6Dac.

${ }^{i i}$ La traducción de este artículo es propia ya que no existe versión en español.

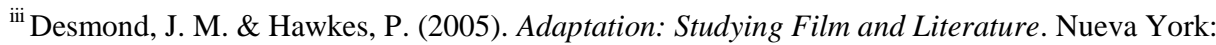
McGraw-Hill. Citado en Leitch, T. (2008). Adaptation Studies at a Crossroads. Oxford: Oxfrod University Press.

${ }^{\text {iv }}$ Cahir, L. C. (2006). Literature into Film: Theory and Practical Approaches. Jefferson, Carolina del Norte: McFarland. Citado en Leitch, T. (2008). Adaptation Studies at a Crossroads. Oxford: Oxfrod University Press.

${ }^{v}$ Disponible en: www.maitrianland.com/textos/mementomoritrad.doc

${ }^{\text {vi } H u b e r, ~ W . ; ~ K e i t e l, ~ E . ~ \& ~ S u ̈ s s, ~ G . ~(2007) . ~ I n t e r m e d i a l i t i e s . ~ T r i e r: ~ E d i t o r i a l ~ c i e n t i ́ f i c a ~ T r i e r . ~ C i t a d o ~ e n: ~ L e i t c h, ~ T . ~}$ (2008). Adaptation Studies at a Crossroads

${ }^{\text {vii }}$ Peter Ravinowitz, estudioso de muy marcado cariz semiótico, distingue cuatro tipos básicos de auditorio: $1^{\circ}$ ) Audiencia actual. $2^{\circ}$ ) Audiencia autorial (el auditorio que toma el texto como una 
comunicación ficticia producida por el autor). $3^{\circ}$ ) Audiencia Narrativa (toma el texto como una comunicación auténtica del narrador). $4^{\circ}$ ) Audiencia Ideal Narrativa (Interpreta la comunicación del narrador según los deseos de éste). Estas distinciones intentan dar cuenta del fenómeno de la lectura, donde los papeles señalados se cumplen simultáneamente. Estos conceptos están desarrollados por el propio Peter Ravinowitz en su obra Verdad en la ficción: Un re-examen de audiencias, en la revista Critical Inquiry. 1977.

viii 'Instinto Básico' (1992), de Paul Verhoeven, mezcla sexo, intriga y dosis de psicología en cantidades equiparables, muy asimilables por un público ávido de morbo.

ix Alfred Hitchcock, (Londres 1899-Los Ángeles 1980). Comenzó su periplo como director en la U.F.A. alemana en los 20. Volvió a Londres y allí en los 30 sus películas lo hicieron famoso. En 1940 llamado por David O. Selznick va a EE.UU., donde se especializa en películas de suspense e intriga detectivesca y de espionaje.

x 'Pánico en la escena' (1950) cuenta la historia de un asesinato entre bastidores de un teatro, creando suspense en torno a las pesquisas de la policía para atrapar al asesino.

xi 'El Golpe' (1973) de George Roy Hill. Es una de las obras maestras del cine de todos los tiempos. El argumento de la misma versa sobre un gran timo «de ahí el título» $(2.000 .000 \$$ de los años 30) cuya víctima es un gángster de apuestas ilegales en Chicago que alardea de buena posición social e intachable honra. Es una especie de nuevo 'Regador regado' ('L' arroseur arrosé') de Louis Lumière en 1895.

xii 'Casa de juegos' de David Mamet (1987). Remedo de 'El Golpe'. El argumento trata de una mujer timada que pretende devolver "el regalo" a sus timadores aliándose con ellos. Acaba matando a uno de los estafadores al ser descubierta por éste. Existe asimismo una segunda parte de 'El Golpe', titulada 'El Golpe II', de Jeremy Kagan en 1983 de menor calidad, pero muy interesante al copiar el esquema narrativo, aunque ya no tan sorpresivamente como sucediera en la cinta original.

xiii Wayne Booth define al "Narrador poco fiable" como el narrador falible, distanciado del autor implícito (que es el que sustenta las normas y valores de la obra). En 'Memento' este concepto es básico para la intriga.

${ }^{\text {xiv }}$ En buena lógica lingüística no puede existir un emisor que sea "él” y no "yo". El origen del texto sólo puede deberse a un "yo", de ahí que Gérard Genette (1983) haya propuesto como términos más exactos, "según el narrador participe o no en el universo ficticio o diégesis los de: narrador homodiegético y narrador heterodiegético. El primero (homodiegético) hace referencia a un yo narrativo y el segundo (heterodiegético) a un él y a veces un tú" en Nouveau discours du récit. (1983) Pág. 92.

${ }^{\mathrm{xv}}$ Los musulmanes no pueden mostrar la figura humana por mandato del Corán. En el cine esta interdicción se limita a la figura de Mahoma. Esto puede ser visto en películas como 'Mahoma, mensajero de Dios' (1976) del egipcio Moustapha Akkad, en la que Mahoma es representado con una cámara subjetiva y nunca visto -sólo sus huellas en el desierto como eficaz metonimia-.

${ }^{x v i}$ En ella se nos dan tres versiones de un mismo accidente automovilístico. Cada una corresponde a uno de los dos intervinientes y a un testigo tartamudo, con cuyo relato el director acompasa humorísticamente la imagen (mediante repeticiones y paradas antinaturales).

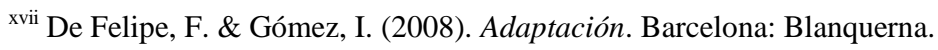

